\title{
Measuring pandemic home-work conditions to determine ergonomic recommendation relevance
}

\author{
Nancy L. Black* and Samuelle St-Onge \\ Faculté d'ingénierie, Université de Moncton, Moncton, New Brunswick, Canada
}

Received 6 May 2021

Accepted 8 September 2021

\begin{abstract}
.
BACKGROUND: Computer-intensive office work associations with health challenges may intensify following COVID-19 pandemic-related changes to home-based office work.

OBJECTIVE: To determine working conditions, perception and physical elements affecting health after pivoting to full time home-work.

METHODS: An online questionnaire addressed physical, productivity, motivation, and work-practice factors. Photos of the worker in their home-work environment showed side and front-back perspectives.

RESULTS: Sixteen questionnaires were received, and 12 respondents supplied photos. Home and office workplace differences varied. Ten felt productivity was affected, most often positively. Four noted increased pain or fatigue intensity, particularly in the eyes, neck / head, lower back, and shoulders. Working posture was not optimal; six didn't use traditional chair-sitting for up to half the day. Forward and backward trunk inclination accounted for at least $10 \%$ of the workday for 12 respondents; lateral inclination affected ten and eight had unsupported legs. Fifteen used an adjustable chair, but photos revealed ergonomic recommendations were not consistently followed. Fourteen participants communicated regularly by telephone, eight only for moderate duration and ten using adapted telephone equipment. Half of the ROSA scores were high.

CONCLUSIONS: Workers forced into telework during the pandemic experience positive and negative impacts. Postures vary more than in offices, potentially increasing health risk.
\end{abstract}

Keywords: Telework, office ergonomics, musculoskeletal disorders, posture, change, COVID-19

\section{Introduction}

Following the declaration of the global COVID19 pandemic in March 2020, employers asked their employees, who were able, to work from home. The large-scale transformation to "telework" (computerbased work from home) imposed by a rapidly developing global pandemic did not follow the usual methodical analysis and investment in home-work office spaces [1,2]. Given the large population newly

*Address for correspondence: Nancy L. Black, Faculté d'ingénierie, Université de Moncton, Moncton, New Brunswick, Canada. E-mail: nancy.black@umoncton.ca. experiencing this change, it is crucial to understand and quantify real office work conditions in workers' homes.

Several articles have studied the impact of teleworking during the pandemic, including consideration of the impact on telework frequency [1], physical discomfort [3, 4], and office equipment use [4, 5]. Some of these consider a particular employer, either in higher education $[3,4,6]$ or a commercial company [7]. In this research, our interests focus on musculoskeletal disorder (MSD) risk while considering the holistic nature of these costly health degradations and including various employers. Since MSDs in office environments are a function of physical factors, 
including posture and duration, and psychophysical elements [8-10], multiple dimensions must be considered. In this study, we consider work practices, worker perception, working tools, physical layout, posture, and adherence to ergonomics recommendations.

\subsection{Background}

A review of research into ergonomics and effects of telework found an "almost unlimited number of factors" that can be studied and can impact research results, from distraction, to environmental impact, inadequate home spaces and isolation [11]. Psychosocial risks and social supports play moderating roles in MSD risk [12].

In contrast, most common physical MSD risk factors of modern computer-intensive office work are postural deviation from neutral, fixation, and exposure duration [13]. Working supports should be arranged to maintain neutral posture of wrists, to respect the normal reach space of the forearm, to avoid neck or trunk rotation, torsion or flexion, to maintain hip flexion between $90^{\circ}$ and $120^{\circ}$, and to support both feet flat on the floor [14]. Computer workers who regularly change posture will have better health and productivity relative to sedentary workplaces [15]; experts recommend standing for at least $25 \%$ of the working day [16]. Physical isolation imposed by working from home makes managing adherence to such recommendations difficult. In the paragraphs that follow, we focus on physical aspects which have been studied in office ergonomics contexts.

Computer work has long been associated with physical discomfort and MSD risk. Multiple studies report that over $60 \%$ of workers engaging in computer-intensive work experience regular physical discomfort in one or more body regions [17-22]. Already in 2004, computer work was associated with increased risk of musculoskeletal disorders (MSDs) particularly in the upper trunk and upper extremities [23], with more recent research focussing concern on back, neck and shoulders $[18,24]$. These statistics consider workers in predefined desk-based office environments with a chair, and traditional desktop computer components, including a separately adjustable computer screen, keyboard, and a pointand-click device ("mouse"). Working with a laptop computer which includes a computer screen, keyboard and mouse in a predefined manner, reduces postural variation [25] and is associated with different postures among male and female college students [26]. The typical, gradual development of MSDs adds to the challenge of intervening in this pandemicimposed telework environment in a sufficient and timely manner.

Office ergonomics is a well-developed field which has given birth to specific tools to quantify ergonomics risks [27]. The Rapid Office Strain Assessment (ROSA) uses a similar format to the Rapid Upper Limb Assessment (RULA) but considers the physical tools specific to a computer-intensive office environment [28] and their effect on physical constraints. Published and verified office-ergonomics questionnaires range in length from 312 items in a call-centre environment [29] to a 37-question checklist considering chair, desk, monitor, keyboard, mouse, telephone and physical environment [30] to equipment-only Yes/No/Not-applicable tools [14]. Most office ergonomics evaluation tools anticipate standard office elements (chair, desk, keyboard, screen, telephone) in a purpose-built environment. Only recent documents like the Canadian Standards Association's (CSA Group's) Office Ergonomics standard (Z412-17) explicitly reflects "new technology and work practices", including non-office workplaces where office work occurs [31].

Physical distancing requirements associated with the COVID-19 global pandemic make remote evaluation necessary. Emerson et al. [32] described how to effectively accomplish office ergonomics evaluation remotely, based on principal computer workstation components, and typical suggestions to limit musculoskeletal pain and symptoms to improve safety and comfort. Blake and Taylor describe successfully using 30 second video recordings in two planes (side, and behind and above) to support remote home office assessments [33]. Indeed, the ROSA has been successfully applied remotely using with photographs if the images include key body areas and typical contextual factors [34].

This study describes home-based office work environments more than 4 months after the global COVID-19 pandemic had been declared.

\subsection{Objective}

The objective of this article is to provide an overview of the variety of both physical and psychophysical work characteristics which may affect the risk of musculoskeletal disorder (MSD) development due to pandemic-imposed work-from-home. This information is important for managers and employers to 
adapt their training and support as a function of this home-based office work.

\section{Methods}

The protocol was approved by the research ethics board of the Université de Moncton (dossier 2021009).

\subsection{Data collection tools}

To measure the work situation, we used two sources: 1) an electronically administered self-report questionnaire including a variety of elements and postures used during office work and 2) photographic evidence. The 15-minute questionnaire consisted of mostly multiple-choice questions. In addition, participants were asked to supply two photos of themselves in their typical posture showing their workstation and office-work elements in frontal and sagittal planes (taking an estimated 5 minutes). Both questionnaire and instructions for taking the photographs were provided in English and French. These data collection tools are described in detail elsewhere [35] and were based on the ROSA tool and public institutions supporting wellness at work [36, 37].

\subsection{Recruitment}

An emailed invitation was sent to the human resource manager at three local employers (public and private) and a call-centre networking organization; in all cases, these representatives subsequently distributed the one-page invitational announcement to their employees.

Typically, all communication between the researchers and participants was electronic. In response to the announcement, potential participants emailed the researchers, who responded with a one-page informed consent form to be filled in. Upon receiving the completed consent form, the researchers communicated a unique alphanumeric participant code which consisted of a letter (indicating workplace), and a 3-digit number, starting with 001 for each workplace. This code was used to complete the questionnaire accessible through a Google Forms link. The two requested photos were sent separately; these were pre-processed to hide individual-identifying elements with an opaque form, and then were saved on a shared research computer disk, associated with the participant code. By coding and pre-processing participant data, the questionnaire and photos were linked while maintaining participant confidentiality.

Questionnaire responses included the few elements required for ROSA scoring that could not be reliably observed from an image. The majority of ROSA analysis required analysis of the photographs, including angular measurement of key postural elements, using free KINOVEA software (version 0.8.15).

\section{Results}

The results section is divided into two parts: questionnaire results and ROSA scores.

\subsection{Questionnaire results}

Sixteen people of working age responded to the questionnaire between October 2020 and January 2021. Twelve of these supplied the requested photos. Given this small sample, only summary statistics results are presented. Questionnaire results are presented over the following sections, divided by participant demographics, work practices, perception of work-at-home environment, impact of home-work on pain and posture, body posture over working day, workstation components, and telephone usage and devices.

\subsubsection{Participant demographics}

Twelve of the 16 respondents were women. The most common age group was 40-49 years (seven participants) followed by 50-59 years (six participants), 30-39 years (two participants) and finally 19-29 years (one participant). Average population standing height was $163.4 \mathrm{~cm}$ (standard deviation $\pm 9 \mathrm{~cm}$ ) with men being nearly $10 \mathrm{~cm}$ taller than women $(169.5 \pm 12.7 \mathrm{~cm}$ and $160.2 \pm 9.2 \mathrm{~cm}$, respectively).

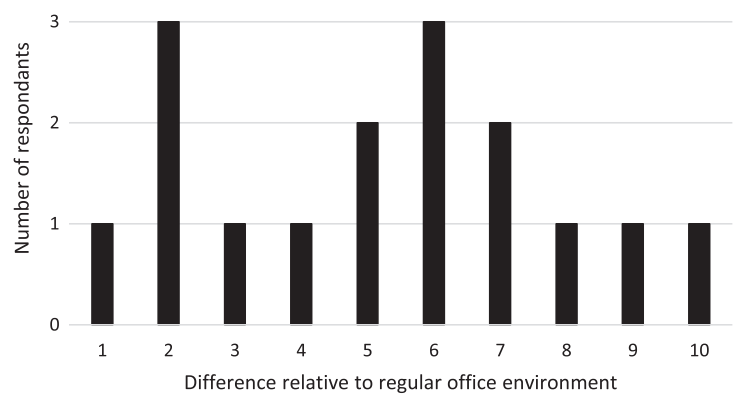

Fig. 1. Number of respondents by perceived difference of home your home office from your work office, on a scale from 1 (no different) to 10 (completely different). 


\subsubsection{Work practices}

When responding to the questionnaire, 15 participants had been working from home for at least 4 months, with the other one working from home for 3 months. Only one had been working from home prior to the pandemic. All worked on the computer for at least one continuous hour or for more than four hours total daily and sat for similarly high daily work periods.

\subsubsection{Perception of work-at-home environment}

Respondents judged the difference between their home-workplace and their office environment on an ordinal scale of 1 (not at all different) to 10 (completely different). All ten values occurred with the most common responses being 2 and 6 (Fig. 1). Nine worked in a spare room, with other locations, in descending order of frequency, being bedroom (three), basement (two), and other common areas (studio, solarium, one each).

\subsubsection{Perception of work-at-home productivity}

Nearly ten of the 16 felt that working at home had impacted their productivity, all of those noting one or more positive impacts, and seven of that same group noting one or more negative impacts (Figs. 2 and 3).

\section{Factors increasing productivity during work-from-home}

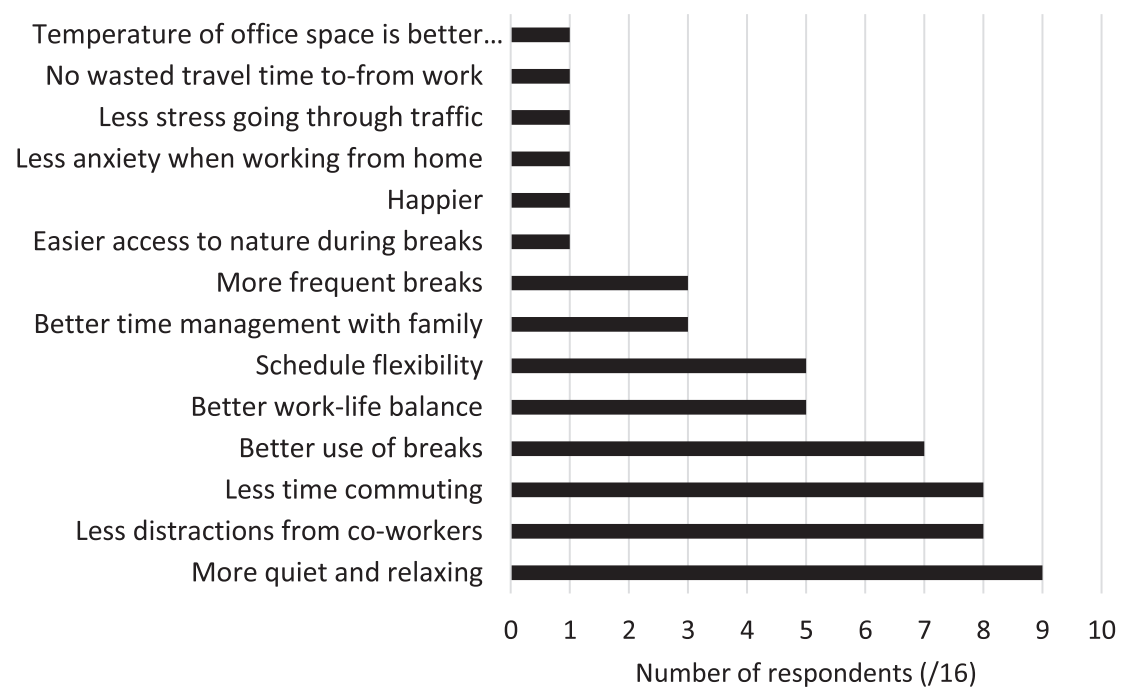

Fig. 2. Responses to "What is causing you to be more productive working from home?". More than one response was possible.

\section{Factors decreasing productivity during work-from-home}

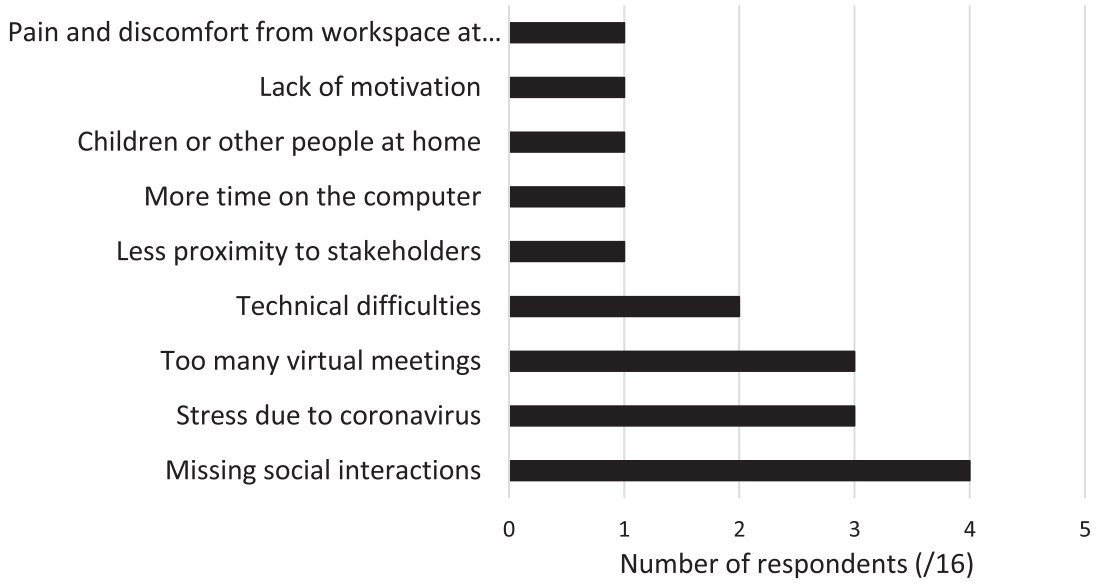

Fig. 3. Responses to "What is causing you to be less productive working from home?" More than one response was possible. 


\subsubsection{Impact of home-work on pain and posture}

Participants rated the intensity of their current typical pain or fatigue relative to the typical levels they experienced in their office environment, and if increased, they provided detail of current intensity on an ordinal scale from 1 (no pain or fatigue) to 10 (the worst pain of your life). Four of the respondents (three women and one man) experienced more pain or fatigue after a day of working at home, compared to working at the office. Among those people, current pain / fatigue ratings by body region varied from 1 to 8 , with average values in of at least 5 in the eyes, neck / head, lower back, and shoulders (Table 1).

\subsubsection{Body posture over working day}

To determine postural MSD risk, respondents estimated the percentage of their working day in different postural classes in $10 \%$ increments.

General working posture was categorized across five predefined options: sitting at a desk, sitting on a couch, sitting on a bed, lying on a bed, or standing at a desk. Sitting at a desk was the most observed category, accounting for all the time for ten of the participants and at least $50 \%$ of the time for the others (Fig. 4). Among the six respondents who varied posture, three varied amongst three postures, and the rest used two postures. None of the respondents included "lying on a bed" among their typical postures.

The questionnaire also inquired about body posture when seated using three categories: sagittal inclination, lateral lean, and leg position (Table 2). Only two consistently maintained an upright sagittal trunk position. Backward leaning occurred more frequently than forward leaning, and indeed reclining was the most common posture for three respondents. Eight regularly leaned to the side. Legs were most likely to be in the recommended posture (2 legs supported) throughout the day (seven respondents).

Table 1

Summary statistics of pain or fatigue intensity by body region across the population with greater-than office pain / fatigue ( 1 to 10 ordinal scale)

\begin{tabular}{lcccc}
\hline Body region & Average & $\begin{array}{c}\text { Standard } \\
\text { deviation }\end{array}$ & Maximum & Minimum \\
\hline Eyes & 5.75 & 2.22 & 8 & 3 \\
Neck / head & 5.50 & 2.38 & 8 & 3 \\
Upper back & 4.50 & 2.08 & 7 & 2 \\
Lower back & 5.00 & 1.41 & 6 & 3 \\
Shoulders & 5.00 & 3.16 & 8 & 1 \\
Wrists & 2.50 & 1.73 & 5 & 1 \\
Hands & 3.00 & 2.71 & 7 & 1 \\
Legs & 3.50 & 2.38 & 6 & 1 \\
\hline
\end{tabular}

\subsubsection{Workstation components}

Workstation components considered in the questionnaire included the chair and computer components including the nature of the computer itself, its screen, and pointing device for data entry. The work surface was assumed to be a large, flat surface, with or without a keyboard tray.

3.1.7.1 Chair. All but one respondent used an adjustable office chair. All adjustable chairs had height adjustability and 13 of these had adjustable armrests. Interestingly, 11 had both back and seat tilt and two had only one or the other of these tilts. Both lumbar support and depth adjustability was present in eight of the chairs, and two had only one or the other.

3.1.7.2 Computer components and locations. Although we did not specifically ask what type of computer respondents used, of the twelve that supplied photographs six had a laptop computer in their workstation in addition to at least one separate computer screen. The others used a desktop computer.

Of the entire respondent population, most (13 of 16) used an external mouse. When using an external mouse, all judged that they held the mouse in a supported (recommended) fashion and maintained the mouse and keyboard on the same (height) work surface. However, only six judged that their mouse was typically in the recommended location (not requiring lateral reach).

All participants judged their wrist postures as neutral when using their keyboard, avoiding problematic lateral deviation and extension. However, two recognized typically raised shoulders, one when keyboarding, and the other due to the work surface height. The principal computer screen was located directly in front for all but one person whose screen was to one side, requiring neck rotation.

\subsubsection{Telephone usage and devices}

Fourteen of the respondents made phone calls during their home-work day. The majority of these (8) spent less than 30 minutes at a time or a total of at most one-hour daily on calls, while four spent somewhat more (less an hour at a time or between one and four hours total daily), and one spent over an hour consecutively on the phone or more than 4 hours total. The telephone was within arms' reach for all required to make phone calls regularly. Telephone devices used included a headset (6), a phone with speaker mode (3), hand-held receiver (3) or a combination of computer-based video calls and hand-held receiver (1). All using hand-held telephones were in 
the "less than 30 minutes at a time or one-hour daily" category.

\subsection{ROSA scoring results}

ROSA elements were calculated whenever possible for all respondents, although since some elements required visualization, the four respondents who did not supply the required two photographs could not be fully evaluated. Furthermore, certain elements could not be determined for three more respondents who submitted photographs, because views were partially obstructed. As a result, ten ROSA final scores were determined for two men and eight women. Average and standard deviation score indicate areas of particular concern (Table 3). Of this population, $50 \%$ were at the level of "further assessment required as soon as possible", that is at least 5 out of a maximum 10 score [28]. A high ROSA score was most frequently due to chair limitations (four respondents scored 5 / 8 for "height and depth", and one scored $7 / 9$ in "arm rest and back support"). Monitor occasionally had a high score (two participants scored $6 / 7$ ).

\section{Discussion}

The population responding was comprised mostly of women (12 of 16), which may be or may not be representative of the general population facing imposed COVID-19-related work-from-home. Although the percentage of women working in offices environments may be closer to $50 \%$ since $52 \%$ of Americans in "management, professional and related occupations" were women, $73 \%$ in "office and administrative support occupations" were women [38]. Since we did not ask about the type of work done in the home-office, we cannot be confident that this population represents the gender distribution in the participating workplaces. Since gender affects perceived musculoskeletal risk factors [39, 40], the presence of both genders in this study is important. In our results increased pain and fatigue intensity affected the subset of participants of both genders in similar proportions to the total study population. Similarly, there was no evident gender-based difference in ROSA scores.

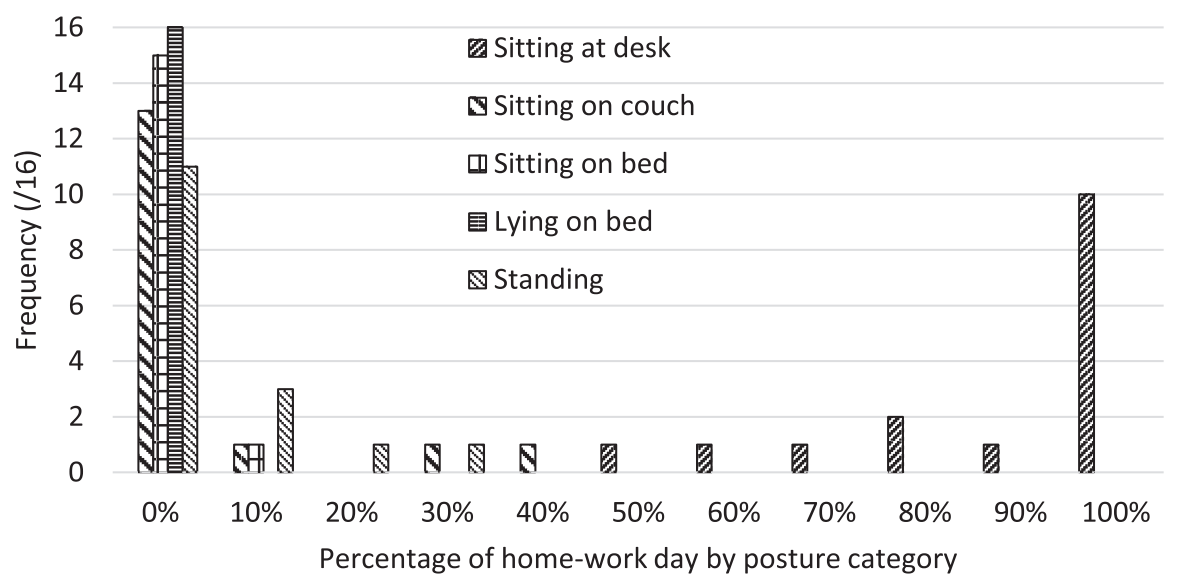

Fig. 4. Distribution of working posturesover typical home-work day across respondent population.

Table 2

Summary statistics of perceived period in typical postures by body region when seated, reported in $10 \%$ increments by participant

\begin{tabular}{llcccc}
\hline Body region & Posture & Average & Standard deviation & Maximum & Minimum \\
\hline Sagittal inclination & Upright (neutral) & $68 \%$ & $26 \%$ & $100 \%$ & $70 \%$ \\
& Backward lean & $19 \%$ & $24 \%$ & $40 \%$ & $0 \%$ \\
Lateral lean* & Forward lean & $13 \%$ & $13 \%$ & $100 \%$ & $0 \%$ \\
& Upright (neutral) & $78 \% *$ & $24 \%$ & $24 \%$ & $0 \%$ \\
Leg posture & Lateral lean & $21 \% *$ & $27 \%$ & $100 \%$ & $0 \%$ \\
& 2 legs supported & $80 \%$ & $15 \%$ & $0 \%$ & $0 \%$ \\
& Crossed at knee & $9 \%$ & $26 \%$ & $10 \%$ & $0 \%$ \\
\hline
\end{tabular}

*One respondent only accounted for $90 \%$ of their day; thus, averages consider less than $100 \%$. 


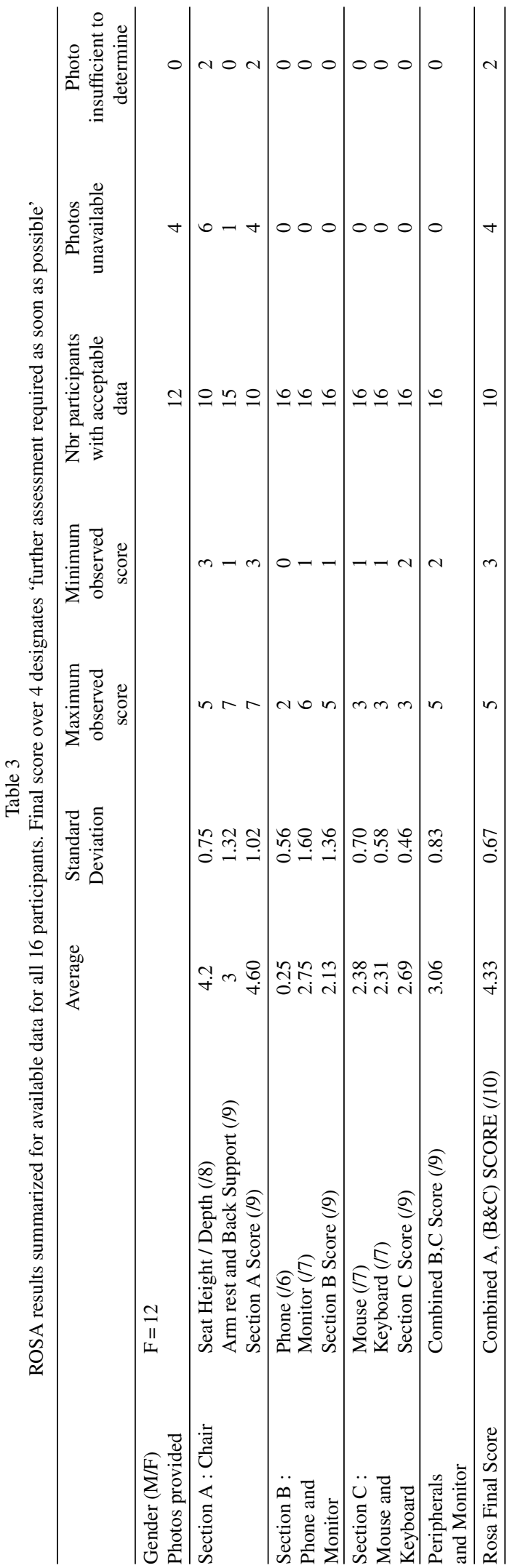

Since standing height of our population was similar to that of an American adult population [41], anthropometric correspondence to workstation elements would be similar to the general population. Participant age was captured by decade, with respondents coming from all age ranges except over 60 years and 13 at least 40 years of age. Since MSDs are more common with increasing age [42], the probability of observing MSD symptoms is greater in this study population than in the general working population which includes all age ranges in similar numbers.

How much the at-home work environment differed from the usual office environment varied widely. This variation may be partially a function of individual perception since we did not provide reference examples. Bedroom, basement, and solarium locations differ more fundamentally than the most frequently cited "spare room". Further questioning of general characteristics of the workspace is warranted to refine the understanding of this factor.

Most respondents recognized that their productivity was affected by working-from-home, and more numerous positive factors were cited than negative factors, consistent with other teleworking populations pre-pandemic [11]. We supplied a predefined list of impact options based on previous studies [11, 36], but participants were able to define their own additional factors. The fact that such factors were deemed important is consistent with observations from a systematic review of the literature into ergonomics and telework [11].

Our questionnaire found only four of 16 respondents experienced greater discomfort and fatigue intensity than in their usual office environment. We expected that discomfort in these improvised office work environments would increase due to an inability to access and optimally locate typical office components. However, a study of two universities found musculoskeletal pain decreased when teleworking within 3 months of the COVID-19 shutdown (April - May 2020 in Spain) [3]. Since our questionnaire did not ask about decreases in pain and fatigue intensity, it is impossible to directly compare these results. However, the fact that 12 of our respondents did not report worsened physical pain and fatigue is important. Greater control over one's work environment is a psychophysical factor associated with reduced MSD risk [10, 12], and was recognized as a positive effect of working from home in this population and could compensate for worsening physical layout. Refinement of questions relating to discomfort should capture all changes - whether positive or negative rel- 
ative to the previous office environment, preferably by individual body region. Using the Standardized Nordic Questionnaire format (36) would allow clear comparative data, but would also lengthen the duration of the questionnaire, possibly reducing future participation.

It is not surprising that half of the ROSA scores calculated with this population suggest that "further assessment follow as soon as possible". Other studies have found average scores of at least this level, and people experiencing pre-existing musculoskeletal pain have significantly higher ROSA scores than those without [43]. The rapid change to working-from-home with the developing COVID19 pandemic due to public health restrictions was expected to be temporary. Where traditional telework changes require justification and are accompanied by ergonomic evaluations and equipment procurement, the uncertainty of a global pandemic precluded such methodical approaches [1]. Furthermore, the economic uncertainty of an extended pandemic-imposed shutdown makes sufficient investment in office equipment to adequately transform one's spare room or solarium doubtful.

On the positive side, physical and psychosocial supports are easily available to support at home office work, often free of charge. Internet-accessible resources are published by publicly supported organizations at no cost $[36,37]$ and recommendations are appearing in the general press [44] suggesting inexpensive adaptations to compensate for ergonomics limitations in a home environment. Indeed, the tendency to improve psychosocial aspects of office work due to increased control of one's work environment, and the potential necessity to move more frequently whether due to discomfort, distraction or some other reason together bode positively for workers in this work-from-home office environment when consistent with ergonomics.

\subsection{Limitations}

While attempts were made to ensure questions asked were consistent with the published literature, this study protocol, including questionnaire combined with the two photographic views, comprises a new measurement tool which has not been validated in a controlled study. In retrospect, some questions would be enhanced by reformulation; for example, asking about improvements, maintenance and worsening of physical discomfort, would be more inclusive, as mentioned earlier. When both questionnaire and photographic information were present for a particular element, questionnaire data were used to determine the elemental ROSA scores, so conclusions depend on reliable self-reporting; the photographs provided useful contextual confirmation for the questionnaire statements. Even with Kinovea's quantitative angular analyses including baseline and segment of interest, some body segments were not sufficiently visible to have confidence in the score (Table 3); in these cases, that score was omitted, and the participant's final ROSA score could not be calculated. While these limitations would be overcome by a closer researcher-employer-respondent relationship, establishment of such relationships would limit the breadth of participating employers and employees.

The data presented here refer to a small population of workers normally in different offices who were forced to work from their home during the COVID-19 pandemic. The variability in home-office environments would already normally be greater than in a purpose-designed office, but these variations are compounded by individual perception of the stresses and opportunities. Thus, the fact that this study included respondents from a variety of employers also increases the probability that, with a small population, this data is not fully representative. Further data collection involving a refined questionnaire tool is warranted.

\section{Conclusion}

This study presents a wide variety of data on individual office work conditions during work-fromhome imposed during an extended public health pandemic. With only 16 participants, our population was too small to determine statistically significant changes with the questions asked. However, the responses to a brief self-administered questionnaire paired with two images showing the respondent in their work environment provide valuable insight into the challenges and successes of traditional office work in non-planned office spaces. These provide a structure for revising ergonomics evaluations and recommendations. Employers and researchers must be sensitive to these home-based office work variations when formulating recommendations to ensure that their results reveal positive health-impacting differences. 


\section{Conflict of interest}

\author{
None to report.
}

\section{Funding}

Funding for this project was provided to the second author through a Mitacs Research Training Award (2020) and the first author's Natural Sciences and Engineering Research Council of Canada Discovery Grant RGPIN-2020-05591.

\section{References}

[1] Belzunegui-Eraso A, Erro-Garcés A. Teleworking in the Context of the Covid-19 Crisis. Sustainability. 2020;12:3662.

[2] Song K. Non-face-to-face home office system for improving work efficiency Home Office Furniture System Development. J Korea Inst Spat Des. 2020;15:15-172.

[3] Rodríguez-Nogueira Ó, Leirós-Rodríguez R, BenítezAndrades JA, et al. Musculoskeletal Pain and Teleworking in Times of the COVID-19: Analysis of the Impact on the Workers at Two Spanish Universities. Int J Environ Res Public Health. 2021;18:31. DOI: 10.3390/ijerph18010031.

[4] Gerding T, Syck M, Daniel D, et al. An assessment of ergonomic issues in the home offices of university employees sent home due to the COVID-19 pandemic. Work Read Mass. 2021;68:981-92. DOI: 10.3233/WOR-205294.

[5] Kotowski SE, Davis KG, Gerding T. Almost a year in: Virtual offices remain an ergonomic trouble spot. Work. 2022;71:319-26. DOI: 10.3233/WOR-211052.

[6] Davis KG, Kotowski SE, Daniel D, et al. The Home Office: Ergonomic Lessons From the "New Normal". Ergon Des Q Hum Factors Appl. 2020;28:4-10.

[7] Yegul F, Açikgöz A, Kazimov Z. ISEs study what happens when no one comes to the office. Ind Manag. 2020;62:23-7.

[8] Redivo VS, Olivier B. Time to re-think our strategy with musculoskeletal disorders and workstation ergonomics. South Afr J Physiother. 2021;77:1490.

[9] Boukerma Z, Behlouli A-L. Musculoskeletal disorders and work-related stress among computer users. Ital J Occup Environ Hyg. 2016;7:72-80.

[10] Devereux JJ, Rydstedt LW, Cropley M. Psychosocial work characteristics, need for recovery and musculoskeletal problems predict psychological distress in a sample of British workers. Ergonomics. 2011;54:840-8.

[11] de Macêdo TAM, Cabral EL dos S, Silva Castro WR, et al. Ergonomics and telework: A systematic review. Work. 2020;66:777-88.

[12] Truchon M, Langlois L. Santé, bien-être et performance organisationnelle chez le personnel d'un établissement d'enseignement supérieur québécois: validation d'un nouveau questionnaire et proposition d'un modéle explicatif: Job Demands-Organizational and Occupational Resources (JD-OOR): rapport de recherche. [Health, wellness and organizational performance among personnel in a post-secondary teaching institution: validation of a new questionnaire and proposal of an explanatory model: Job Demands - Organizational and Occupational
Resources (JD-OOR): Research Report] Québec: Université Laval. 2019. Available from: https://corpus.ulaval.ca/ jspui/bitstream/20.500.11794/37235/1/Truchon_Manon_1311-19.pdf.

[13] Sasikumar V, Binoosh S champakkadayil A basheer. A model for predicting the risk of musculoskeletal disorders among computer professionals. Int J Occup Saf Ergon JOSE. 2018;26:1-13.

[14] WorkSafe NB. Computer Workstation Ergonomics, https:// www.worksafenb.ca/media/61622/computer_workstation_ ergonomics.pdf (2020).

[15] Davis KG, Kotowski SE. Stand Up and Move; Your Musculoskeletal Health Depends on It. Ergon Des. 2015;23: 9-13.

[16] Buckley JP, Hedge A, Yates T, et al. The sedentary office: an expert statement on the growing case for change towards better health and productivity. Br J Sports Med. 2015;49:1357-62.

[17] Bhanderi D, Choudhary SK, Parmar L, et al. A study of occurrence of musculoskeletal discomfort in computer operators. Indian J Community Med. 2008;33:65.

[18] Ardahan M, Simsek H. Analyzing musculoskeletal system discomforts and risk factors in computer-using office workers. Pak J Med Sci. 2016;32:1425-9.

[19] Janwantanakul P, Pensri P, Jiamjarasrangsri V, et al. Prevalence of self-reported musculoskeletal symptoms among office workers. Occup Med. 2008;58:436-8.

[20] Green BN. A literature review of neck pain associated with computer use: public health implications. J Can Chiropr Assoc. 2008;52:161-7.

[21] Kaliniene G, Ustinaviciene R, Skemiene L, et al. Associations between musculoskeletal pain and work-related factors among public service sector computer workers in Kaunas County, Lithuania. BMC Musculoskelet Disord. 2016;17:420-31.

[22] Cho C-Y, Hwang Y-S, Cherng R-J. Musculoskeletal Symptoms and Associated Risk Factors Among Office Workers With High Workload Computer Use. J Manipulative Physiol Ther. 2012;35:534-40.

[23] Juul-Kristensen B, Søgaard K, Strøyer J, et al. Computer users' risk factors for developing shoulder, elbow and back symptoms. Scand J Work Environ Health. 2004;30: 390-8.

[24] d'Errico A, Caputo P, Falcone U, et al. Risk Factors for Upper Extremity Musculoskeletal Symptoms among Call Center Employees. J Occup Health. 2010;52:115-24.

[25] Yu Z, James C, Edwards S, et al. Differences in posture kinematics between using a tablet, a laptop, and a desktop computer in sitting and in standing. Work. 2018;61: 257-66.

[26] Bubric K, Hedge A. Differential patterns of laptop use and associated musculoskeletal discomfort in male and female college students. Work. 2016;55:663-71.

[27] Levanon Y, Lerman Y, Gefen A, et al. Validity of the modified RULA for computer workers and reliability of one observation compared to six: Ergonomics: Vol 57, No 12. Ergonomics. 2014;57:1856-63.

[28] Sonne M, Villalta DL, Andrews DM. Development and evaluation of an office ergonomic risk checklist: ROSA - Rapid office strain assessment. Appl Ergon. 2012;43: 98-108.

[29] Norman K, Alm H, Tornqvist EW, et al. Reliability of a questionnaire and an ergonomic checklist for assessing working conditions and health at call centres. Int J Occup Saf Ergon JOSE. 2006;12:53-68. 
[30] Pereira MJ, Straker LM, Comans TA, et al. Inter-rater reliability of an observation-based ergonomics assessment checklist for office workers. Ergonomics. 2016;59:1606-12.

[31] Z412-17 - Office ergonomics - An application standard for workplace ergonomics, https://www.csagroup.org/store/ product/ (accessed 26 April 2021).

[32] Emerson S, Emerson K, Fedorczyk J. Computer Workstation Ergonomics: Current Evidence for Evaluation, Corrections, and Recommendations for Remote Evaluation. J Hand Ther. 2021;34:166-178. DOI: 10.1016/j.jht.2021.04.002

[33] Blake J, Taylor C. Overcoming the Challenges of Remote Home Office Assessments. In: Black NL, Neumann WP, Noy I (eds) Proceedings of the 21st Congress of the International Ergonomics Association (IEA 2021). Cham: Springer International Publishing, 2022;221:13-20.

[34] Liebregts J, Sonne M, Potvin JR. Photograph-based ergonomic evaluations using the Rapid Office Strain Assessment (ROSA). Appl Ergon. 2016;52:317-24. doi: 10.1016/j.apergo.2015.07.028.

[35] St-Onge S, Black NL. Ergonomic Evaluation of Home Workspaces During the Coronavirus Pandemic. In: Proceedings of the 21st Congresss of the International Ergonomics Association (IEA 2021). Cham: Springer Nature Switzerland, 2022;222:845-51.

[36] OHCOW. Ergonomic Tips for Temporary Home Workstations...3 Months Later, https://www.ohcow.on.ca/news/ ergonomic-tips-for-temporary-home-workstations3-mon ths-later.html (accessed 8 February 2021).

[37] Government of Canada, Canadian Centre for Occupational Health and Safety. Work-related Musculoskeletal Disorders (WMSDs) - Risk Factors: OSH Answers, https://www.ccohs.ca/ (2021, accessed 10 February 2021).
[38] Bureau of Labor Statistics. Labor Force Statistics from the Current Population Survey CPS CPS Program Links. 11., https://www.bls.gov/cps/cpsaat11.htm (22 January 2021).

[39] Busto Serrano N, Suérez Sánchez A, Sánchez Lasheras $\mathrm{F}$, et al. Identification of gender differences in the factors influencing shoulders, neck and upper limb MSD by means of multivariate adaptive regression splines (MARS). Appl Ergon. 2020;82:102981.

[40] Collins JD, O'Sullivan LW. Musculoskeletal disorder prevalence and psychosocial risk exposures by age and gender in a cohort of office based employees in two academic institutions. Int J Ind Ergon. 2015;46:85-97.

[41] Fryar CD, Carroll MD, Gu Q, et al. Anthropometric Reference Data for Children and Adults: United States, 2015-2018. Natl Cent Health Stat Vital Health Stat; 3, https://www.cdc.gov/nchs/data/series/sr_03/sr03046-508.pdf (2021).

[42] Okunribido O, Wynn T. Ageing and work-related musculoskeletal disorders. Review of Recent Litterature RR799, Derbyshire, UK: Health and Safety Executive.

[43] Rodrigues MS, Leite RDV, Lelis CM, et al. Differences in ergonomic and workstation factors between computer office workers with and without reported musculoskeletal pain. Work. 2017;57:563-72.

[44] Shilton AC. Three Stretches to Tend to the Aches and Pains of Working From Home - The New York Times. The New York Times, https://www.nytimes.com/2020/05/19/ well/three-stretches-to-tend-to-the-aches-and-pains-of-wor king-from-home.html (2020, accessed 6 May 2021). 